\title{
ESPAÇOS LIVRES PÚBLICOS E ÁREAS INSTITUCIONAIS COM USOS ALTERADOS - MICRORREGIÃO 14 - DE PRESIDENTE PRUDENTE-SP
}

\author{
Camila Le Bourlegat, Valquiria Luiz do Amaral, Marcos Norberto Boin, Yeda Ruiz Maria \\ Universidade do Oeste Paulista - UNOESTE. Curso de Arquitetura e Urbanismo, Presidente Prudente - SP. E-mail: \\ yeda rm@hotmail.com
}

\begin{abstract}
RESUMO
O "direito de ir e vir" está assegurado pela nossa Constituição em seu inciso XV do art. 5‥ Esse direito porém só se estabelece à partir de um espaço público livre que assume grande importância no contexto de uma cidade. Devem, portanto, existir lugares onde todos possam ter livre locomoção, permanência, entradas ou saídas, movimentos esses ligados ao bem-estar individual e coletivo. Para que esses direitos sejam garantidos, o contexto urbano deve contemplar a forma de ruas, praças, largos, pátios, parques, jardins, corredores externos, vilas e vielas. Em 19 de dezembro de 1979, através da Lei Federal no 6.766, o Governo Federal atribui aos Estados e Municípios o papel de controlar o uso, ocupação e parcelamento do solo urbano e ainda garantir a existência de áreas livres e de lazer no espaço urbano.

$\mathrm{Na}$ cidade de Presidente Prudente, áreas de lazer e institucionais aprovadas nos loteamentos urbanos foram disponibilizadas pelo poder público local para outros usos. Esta pesquisa busca identificar essa realidade na microrregião 14 e seus respectivos loteamentos.

Palavras-chave: Espaço público. Espaço livre. Área de lazer. Área institucional. Microrregião 14. Presidente Prudente - SP.
\end{abstract}

\section{FREE PUBLIC SPACES AND INSTITUTIONAL AREAS WITH ALTERED USES - MICRO 14 - PRESIDENTE PRUDENTE-SP}

\begin{abstract}
The "right to come and go" is guaranteed by our Constitution in item XV of art. 5th. This right however is only established starting from a free public space that assumes great importance in the context of a city. Should therefore be places where everyone can have free mobility, permanence, inputs or outputs, movements linked to individual and collective well-being. For these rights are guaranteed, the urban context should contemplate the form of streets, squares, courtyards, parks, gardens, exterior corridors, villages and alleys. On December 19, 1979, by Federal Law No. 6766, the Federal Government grants to states and municipalities the role of controlling the use, occupation and division of urban land and still ensure the existence of free and leisure areas in the urban space.

In the city of Presidente Prudente, recreation areas and institutional adopted in urban allotments were provided by the local government for other uses. This research seeks to identify this reality in micro 14 and their respective subdivisions.
\end{abstract}

Keywords: Public Space. Free space. Recreation area. Institutional area. Microrregião 14 Presidente Prudente - SP. 


\section{INTRODUÇÃO}

Segundo Souza (2003), áreas livres são espaços projetáveis, geralmente não edificados, que possuem algum elemento configurador, tais como as vias de acesso, o entorno e as edificações adjacentes.

Ainda para Souza (2003), esses espaços livres, exercem um papel importante na sociedade contemporânea, abrangendo uma função social à medida que possibilitam o encontro e o lazer entre os indivíduos; função organizacional a partir do momento em que se organizam uma infra estrutura na cidade e configuram o desenho urbano; função ecológica quando estimulam áreas de proteção ambiental e função cultural já que fortalecem uma identidade local.

Para Cambraia (2009) as cidades são um sistema de parcelamentos do solo, regulares ou irregulares, espontâneos ou planejados, que subdividem o terreno em lotes por meio de ruas e avenidas, para a ocupação por edificações, ruas e demais usos urbanos.

É no momento do projeto de um loteamento que se desenha a base da futura paisagem, que segundo Cambraia (2009), esta noção deveria nortear a pesquisa de soluções alternativas para a paisagem urbana, de forma a utilizar o potencial dos recursos e processos disponíveis, naturais e sociais, em traçados agradáveis e legíveis.

A área institucional será formada por escolas, postos de saúde e por outros equipamentos comunitários destinados ao atendimento dos futuros moradores daquele empreendimento, conforme prevê a Lei Federal no 6.766/79.

Fica também assegurada à população, através do Estatuto da Cidade (Lei № 10.257/2001) que a "política urbana tem por objetivo ordenar o pleno desenvolvimento das funções sociais da cidade e da propriedade urbana, mediante [...]: V - oferta de equipamentos urbanos e comunitários, transporte e serviços públicos adequados aos interesses e necessidades da população e às características locais" (art.2ํ).

A Constituição Estadual Paulista em seu art. 180 também protege as áreas reservadas nos loteamentos para uso comum da população, não permitindo alteração de sua finalidade.

Em nível municipal tem-se o Plano Diretor (Lei no 154/2008) da cidade de Presidente Prudente, no interior do estado de São Paulo, aprovado em 1996 e revisado em 2008. Por esta lei, que dispõe sobre o parcelamento do solo urbano em Presidente Prudente, em seu artigo 12, fica estabelecido que os loteamentos "deverão atender, pelo menos, os seguintes requisitos:

I - as áreas públicas serão proporcionais à densidade de ocupação prevista para a gleba;

II - as áreas públicas, depois de descontadas as áreas de preservação, não serão inferiores a 35\% (trinta e cinco por cento) da gleba total; 
III - as áreas públicas compor-se-ão, no mínimo de:

a) Áreas institucionais: $5 \%$ (cinco por cento) a 10\% (dez por cento) da área loteável, a critério do órgão responsável pelo Planejamento do município, sendo isolada pelo Sistema Viário;

b) Áreas de lazer: $10 \%$ (dez por cento) a 15\% (quinze por cento) da área loteável;

c) Sistema viário ou arruamento; mínimo $20 \%$ (vinte por cento) da área loteável;

d) Áreas de preservação, quando for o caso;

e) Áreas "NON AEDIFICANDI", quando for o caso."

Com base nestes conceitos apresentados e no que a lei institui, em nível federal, estadual e municipal, busca-se, por meio desta pesquisa, realizar um levantamento de usos dos espaços livres públicos e áreas institucionais de Presidente Prudente - SP, mais especificamente os bairros que compõe a microrregião 14: Jardim Santa Filomena, Residencial Itapuã, Jardim Itapura I e II, Parque Residencial Jarina, Parque Furquim.

\section{DESENVOLVIMENTO}

Realizou-se um levantamento bibliográfico para base conceitual sobre os termos: áreas livres públicas e áreas institucionais, bem como outros assuntos relacionados ao tema que se demonstrem pertinentes.

Em uma segunda fase fez-se uma pesquisa documental em busca de políticas, ações voltadas às áreas livres públicas e áreas institucionais, legislação municipal, estadual e federal relacionadas ao parcelamento, uso e ocupação do solo urbano, mapeamentos de aspectos como: estrutura urbana municipal, localização e mapeamento dos bairros constituintes da microrregião 14 e uso atual dessas áreas.

Para a conclusão dos trabalhos a terceira fase contou com o levantamento físico territorial como objetivo de verificar in loco os aspectos relativos ao uso e ocupação do solo, equipamentos e serviços, a localização e a conformidade dos usos as quais foram destinadas, conforme detalhamento abaixo.

A escritura 237/15 faz referência a uma área de lazer localizada a rua Ramos Barrios, entretanto, atualmente a área encontra-se loteada e ocupada por residências. Segundo levantamento em 1987 foi permitido o uso da área por uma escola de samba, já em 1990 esta área foi doada para a Prudenco, através das leis 2883/89 e 2894/89 como parte de um projeto de desfavelamento.

A escritura 2097/12 faz referência a uma área verde localizada a rua Dolores Medina Espinosa, entretanto, tem-se a informação de que a área permanece invadida, fato constatado em 
19/junho/2012, que identificou uma invasão de barracos, gerando uma autuação e processo administrativo de número 19247/12 para apuração.

As escrituras 238/75 (Av. Ibrain Nobre); 241/75 (Rua Aquiles Tolomei) e 239/75 (Rua Ramon Barrios) fazem referências a áreas de lazer, entretanto, após vistoria no local, constatou-se que a mesma está loteada com residências. Tem-se a informação que em 1990 essa área havia sido doada à Prudenco através das leis 2883/89 e 2894/89 como parte de um projeto de desfavelamento. Em 1991 a doação foi rescindida devendo a área ter sido retornada para o sistema de Recreio.

A escritura 947/83 faz referência a uma área de lazer, entretanto em 1987 foi doada a CRHIS (Companhia Regional de Habitações de interesse social), hoje conjunto habitacional Professor Benedito Ap. do Lago.

A escritura 948/83 registrada como área de lazer com área total de $26957,55 \mathrm{~m}^{2}$, sendo uma área de 18598,55 m² doada ao Sanatório Alan Kardek e restante da área $8359 \mathrm{~m}^{2}$ desocupada.

A escritura 951/83 faz referência a área de lazer, porem no "programa autocad" no site da Prefeitura Municipal de Presidente Prudente está como área institucional. Em 1989 foi doada a Prudenco, retornando a PMPP em 1991. Em 2000 foi permitido uso parcialmente pela Comunidade Evangélica Ágape, entretanto em 2001 foi revogado. Atualmente encontra-se parcialmente invadida, aguardando decisão judicial.

A escritura 952/83 e escritura 1682/06, são áreas institucionais, com área total de 23646,44 $\mathrm{m}^{2}$. Sendo área de $4000 \mathrm{~m}^{2}$ doada e ocupada pela Associação Dos Viajantes e Representantes da Alta Sorocabana; outra parte com área de $10000 \mathrm{~m}^{2}$ doada a SEMEPP, ocupada pelo Centro Esportivo Antônio Benites; área de 9646,44 $\mathrm{m}^{2}$ doada e ocupada pela associação filantrópica de Proteção aos cegos.

A escritura 953/83, registrada como área de lazer de área total de $14423.80 \mathrm{~m}^{2}$, com 10230,33 $\mathrm{m}^{2}$ feito doação a instituição Escola Pedro Furquim. Com uma pequena área de 4193,47 $\mathrm{m}^{2}$ para lazer desocupada.

A escritura 171/50 faz referência a área remanescente, sendo uma área de $59883.00 \mathrm{~m}^{2}$ doada a ADPM e área com $2217.84 \mathrm{~m}^{2}$ doada a Sabesp.

Existem 2 áreas de lazer sem escrituras, entertanto no site da prefeitura está como área de lazer. Uma está na Av. JK de Oliveira esquina com a Rua Edivar de Oliveira com área total de $6330.44 \mathrm{~m}^{2}$ com ocupação atual pela Sub Estação da CAIUA. A outra na Av. JK de Oliveira esquina com a Rua Luiz Carlos Ferrari, hoje construído o "Lar Santa Filomena” com área total de 11153 m². 


\section{CONCLUSÃO}

Após ampla discussão sobre o que a Lei Federal no 6.766/79 assegura aos moradores de áreas urbanas, foi possível confrontar diversas situações onde, áreas urbanas foram definidas para diversos fins e desvirtuadas de sua finalidade básica, o que é vedado pelo Art. 17 da Lei 6766/79, conforme se percebe abaixo:

Art. 17. Os espaços livres de uso comum, as vias e praças, as áreas destinadas a edifícios públicos e outros equipamentos urbanos, constantes do projeto e do memorial descritivo, não poderão ter sua destinação alterada pelo loteador, desde a aprovação do loteamento, salvo as hipóteses de caducidade da licença ou desistência do loteador, sendo, neste caso, observadas as exigências do art. 23 desta Lei.

Como a ferramenta necessária para essa ação, demanda do conhecimento de documentos muitas vezes de difícil acesso, isso acaba por entravar qualquer tomada de ação por parte dos moradores.

Percebe-se que existe todo um aparato legal que possibilita o crescimento ordenado de uma cidade e seu entorno, entretanto, a estrutura administrativa existente muitas vezes não contribui para esse fim, buscando talvez alguns favorecimentos, mesmo em detrimento aos moradores, ao bairro e à cidade.

É preciso muita vontade política para desengavetar antigos processos de desapropriação e trazer à tona mudanças que beneficiam aqueles que são o foco principal das leis vigentes.

As universidades e suas iniciações científicas vêm agregar forças nesse sentido, possibilitando assim uma força de coesão beneficiando os bairros, a cidade e o ambiente.

\section{REFERENCIAS}

BRASIL. Lei Federal no 6.766, de 19 de dezembro de 1979. Dispõe sobre o Parcelamento do Solo Urbano e dá outras providências. Diário Oficial da União, Brasília, 20 dez. 1979. P. 19.457

CAMBRAIA, Maria Aparecida Seabra de Carvalho. Espaços livres públicos em loteamentos urbanos - 2009. 261f. : II. Dissertação (Mestrado) - Universidade Federal de Minas Gerais, Escola de Arquitetura.

COSTA, Stael Alvarenga Pereira et al. Os espaços livres na paisagem de Belo Horizonte. Paisagem ambiente, São Paulo, n.26, 2009.

CUNHA. R.D.A. Os espaços públicos abertos e as leis de uso e ocupação do solo: uma questão de qualidade para ambientes sustentáveis. III Enecs - Encontro Nacional sobre Edificações e Comunidades Sustentáveis. 2003. 
GOMES, C. N. B.; CHIESA, P. Sistema de Espaços Livres em Curitiba: tradição, posturas e práticas locais. In: KAHTOUNI, S; MAGNOLI, M. M.; TOMINAGA, Y. (ORG). Discutindo a Paisagem. São Carlos: RiMa Editora, v. 1, p. 141-170, 2006 (Coleção Paisagem Aberta).

SERPA, ÂNGELO. Os Espaços livres de Edificação nas Periferias Urbanas um Diagnóstico Preliminar em São Paulo e Salvador. Paisagem Ambiente: Ensaios, São Paulo, n.10, p.1890216, dez. 1997.

SOUZA, Juliana Castro. Análise da Paisagem: Instrumento de Intervenção nos Espaços Livres da Lagoa da Conceição - Florianópolis. 2003. 103 p. Dissertação (Mestrado em Engenharia de Produção) - Universidade Federal de Santa Catarina, Florianópolis. 